DOI: 10.2478/awutm-2018-0009 DE GRUYTER
OPEN
Analele Universitătiii de Vest, Timişoara

Seria Matematică - Informatică

LVI, 1, (2018), 136- 148

\title{
Strong Convergence Theorems for Hybrid Mixed Type Nonlinear Mappings in Banach Spaces
}

Gurucharan Singh Saluja ${ }^{1} 2$

\begin{abstract}
In this paper, we introduce a new two-step iteration scheme of hybrid mixed type for two asymptotically nonexpansive self mappings and two asymptotically nonexpansive non-self mappings in the intermediate sense and establish some strong convergence theorems for mentioned scheme and mappings in Banach spaces. Our results extend and generalize the corresponding results recently announced by Wei and Guo [16] (Comm. Math. Res. 31(2015), 149-160) and many others.
\end{abstract}

AMS Subject Classification (2000). 47H09; 47H10; 47J25

Keywords. Asymptotically nonexpansive mapping, non-self asymptotically nonexpansive mappings in the intermediate sense, new two-step iteration scheme of hybrid mixed type, common fixed point, Banach space, strong convergence

\section{Introduction and Preliminaries}

Let $K$ be a nonempty subset of a real Banach space $E$. Let $T: K \rightarrow K$ be a nonlinear mapping, then we denote the set of all fixed points of $T$ by $F(T)$.

\footnotetext{
${ }^{1}$ Department of Mathematics, Govt. N. P. G., College of Science, Raipur, India

${ }^{2}$ Department of Mathematics, Govt. Kaktiya P. G. College, Jagdalpur, India, saluja1963@gmail.com
} 
The set of common fixed points of four mappings $S_{1}, S_{2}, T_{1}$ and $T_{2}$ will be denoted by $F=F\left(S_{1}\right) \bigcap F\left(S_{2}\right) \bigcap F\left(T_{1}\right) \bigcap F\left(T_{2}\right)$ and $\mathbf{N}$ denotes the set of all positive integers.

A mapping $T: K \rightarrow K$ is said to be asymptotically nonexpansive [3] if there exists a sequence $\left\{k_{n}\right\}$ in $[1, \infty)$ with $\lim _{n \rightarrow \infty} k_{n}=1$ such that

$$
\left\|T^{n}(x)-T^{n}(y)\right\| \leq k_{n}\|x-y\|, \forall x, y \in K, n \in \mathbf{N} .
$$

The class of asymptotically nonexpansive mappings was introduced by Goebel and Kirk [3] as a generalization of the class of nonxpansive mappings. They proved that if $K$ is a nonempty closed convex subset of a real uniformly convex Banach space and $T$ is an asymptotically nonexpansive mapping on $K$, then $T$ has a fixed point.

Example 1.1. (See [3]) Let $D$ be the closed unit ball in the Hilbert space $H=\ell_{2}$ and $T: D \rightarrow D$ a mapping defined by

$$
T\left(x_{1}, x_{2}, x_{3}, \ldots\right)=\left(0, x_{1}^{2}, a_{2} x_{2}, a_{3} x_{3}, \ldots\right)
$$

where $\left\{a_{i}\right\}$ is a sequence of real numbers such that $0<a_{i}<1$ and $\prod_{i=2}^{\infty} a_{i}=\frac{1}{2}$.

Then

$$
\|T(x)-T(y)\| \leq 2\|x-y\| \text { for all } x, y \in D,
$$

that is, $T$ is Lipschitzian, but not nonexpansive.

Observe that

$$
\left\|T^{n}(x)-T^{n}(y)\right\| \leq 2\left(\prod_{i=2}^{n} a_{i}\right)\|x-y\| \text { for all } x, y \in D, n \geq 2 .
$$

Here $k_{n}=2 \prod_{i=2}^{n} a_{i} \rightarrow 1$ as $n \rightarrow \infty$. Therefore $T$ is an asymptotically nonexpansive mapping.

Definition 1.1. A subset $K$ of a Banach space $E$ is said to be a retract of $E$ if there exists a continuous mapping $P: E \rightarrow K$ (called a retraction) such that $P(x)=x$ for all $x \in K$. If, in addition $P$ is nonexpansive, then $P$ is said to be a nonexpansive retract of $E$.

If $P: E \rightarrow K$ is a retraction, then $P^{2}=P$. A retract of a Hausdorff space must be a closed subset. Every closed convex subset of a uniformly convex Banach space is a retract. 
Definition 1.2. ([1]) Let $K$ be a nonempty subset of a real Banach space $E$ and let $P: E \rightarrow K$ be a nonexpansive retraction of $E$ onto $K$. A non-self mapping $T: K \rightarrow E$ is said to be asymptotically nonexpansive if there exists a sequence $\left\{k_{n}\right\} \subset[1, \infty)$ with $\lim _{n \rightarrow \infty} k_{n}=1$ such that

$$
\left\|T(P T)^{n-1}(x)-T(P T)^{n-1}(y)\right\| \leq k_{n}\|x-y\|
$$

for all $x, y \in K$ and $n \in \mathbf{N}$.

In 2004, Chidume, Shahazad and Zegeye [2] introduced the concept of non-self asymptotically nonexpansive mappings in the intermediate sense as follows.

Definition 1.3. Let $K$ be a nonempty subset of a real Banach space $E$ and let $P: E \rightarrow K$ be a nonexpansive retraction of $E$ onto $K$. A non-self mapping $T: K \rightarrow E$ is said to be asymptotically nonexpansive in the intermediate sense if $T$ is uniformly continuous and

$$
\limsup _{n \rightarrow \infty} \sup _{x, y \in K}\left(\left\|T(P T)^{n-1}(x)-T(P T)^{n-1}(y)\right\|-\|x-y\|\right) \leq 0 .
$$

Example 1.2. Let $X=\mathbb{R}$ be a normed linear space, $K=[0,1]$ and $P$ be the identity mapping. For each $x \in K$, we define

$$
T(x)=\left\{\begin{array}{cc}
k x, & \text { if } x \neq 0, \\
0, & \text { if } x=0,
\end{array}\right.
$$

where $0<k<1$. Then

$$
\left|T^{n} x-T^{n} y\right|=k^{n}|x-y| \leq|x-y|
$$

for all $x, y \in K$ and $n \in \mathbf{N}$.

Thus $T$ is an asymptotically nonexpansive mapping with constant sequence $\{1\}$ and

$$
\begin{aligned}
\limsup _{n \rightarrow \infty}\left\{\left|T^{n} x-T^{n} y\right|-|x-y|\right\} & =\limsup _{n \rightarrow \infty}\left\{k^{n}|x-y|-|x-y|\right\} \\
& \leq 0
\end{aligned}
$$

because $\lim _{n \rightarrow \infty} k^{n}=0$ as $0<k<1$, for all $x, y \in K, n \in \mathbf{N}$ and $T$ is continuous. Hence $T$ is an asymptotically nonexpansive mapping in the intermediate sense. 
Example 1.3. Let $X=\mathbb{R}, K=\left[-\frac{1}{\pi}, \frac{1}{\pi}\right],|\lambda|<1$ and $P$ be the identity mapping. For each $x \in K$, define

$$
T(x)=\left\{\begin{array}{cl}
\lambda x \sin (1 / x), & \text { if } x \neq 0 \\
0, & \text { if } x=0
\end{array}\right.
$$

Clearly $F(T)=\{0\}$ and $\left\{T^{n} x\right\} \rightarrow 0$ uniformly on $K$ as $n \rightarrow \infty$. Thus

$$
\limsup _{n \rightarrow \infty}\left\{\left|T^{n} x-T^{n} y\right|-|x-y| \vee 0\right\}=0
$$

for all $x, y \in K$. Hence $T$ is an asymptotically nonexpansive mapping in the intermediate sense (ANI in short), but it is not a Lipschitz mapping. In fact, suppose that there exists $\lambda>0$ such that $|T x-T y| \leq \lambda|x-y|$ for all $x, y \in K$. If we take $x=\frac{2}{5 \pi}$ and $y=\frac{2}{3 \pi}$, then

$$
|T x-T y|=\left|\lambda \frac{2}{5 \pi} \sin \left(\frac{5 \pi}{2}\right)-\lambda \frac{2}{3 \pi} \sin \left(\frac{3 \pi}{2}\right)\right|=\frac{16 \lambda}{15 \pi},
$$

whereas

$$
\lambda|x-y|=\lambda\left|\frac{2}{5 \pi}-\frac{2}{3 \pi}\right|=\frac{4 \lambda}{15 \pi},
$$

and hence it is not an asymptotically nonexpansive mapping.

In 2004, Chidume et al [2] studied the following iteration scheme:

$$
\begin{aligned}
x_{1} & =x \in K, \\
x_{n+1} & =P\left(\left(1-\alpha_{n}\right) x_{n}+\alpha_{n} T(P T)^{n-1} x_{n}\right), n \geq 1,
\end{aligned}
$$

where $\left\{\alpha_{n}\right\}$ is a sequence in $(0,1)$, and $K$ is a nonempty closed convex subset of a real uniformly convex Banach space $E, P$ is a nonexpansive retraction of $E$ onto $K$, and proved some strong and weak convergence theorems for asymptotically nonexpansive non-self mappings in the intermediate sense in the framework of uniformly convex Banach spaces.

In 2006, Wang [15] generalized the iteration process (1.3) as follows:

$$
\begin{aligned}
x_{1} & =x \in K, \\
x_{n+1} & =P\left(\left(1-\alpha_{n}\right) x_{n}+\alpha_{n} T_{1}\left(P T_{1}\right)^{n-1} y_{n}\right), \\
y_{n} & =P\left(\left(1-\beta_{n}\right) x_{n}+\beta_{n} T_{2}\left(P T_{2}\right)^{n-1} x_{n}\right), n \geq 1,
\end{aligned}
$$

where $T_{1}, T_{2}: K \rightarrow E$ are two asymptotically nonexpansive non-self mappings and $\left\{\alpha_{n}\right\},\left\{\beta_{n}\right\}$ are real sequences in $[0,1)$, and proved some strong and 
weak convergence theorems for asymptotically nonexpansive non-self mappings. Convergence results have been given by numerous authors in different spaces using different iterative schemes for asymptotically nonexpansive self (or non-self) mappings. For example, see [4-8] among others.

In 2012, Guo et al. [9] generalized the iteration process (1.4) as follows:

$$
\begin{aligned}
x_{1} & =x \in K, \\
x_{n+1} & =P\left(\left(1-\alpha_{n}\right) S_{1}^{n} x_{n}+\alpha_{n} T_{1}\left(P T_{1}\right)^{n-1} y_{n}\right), \\
y_{n} & =P\left(\left(1-\beta_{n}\right) S_{2}^{n} x_{n}+\beta_{n} T_{2}\left(P T_{2}\right)^{n-1} x_{n}\right), n \geq 1,
\end{aligned}
$$

where $S_{1}, S_{2}: K \rightarrow K$ are two asymptotically nonexpansive self mappings and $T_{1}, T_{2}: K \rightarrow E$ are two asymptotically nonexpansive non-self mappings and $\left\{\alpha_{n}\right\},\left\{\beta_{n}\right\}$ are real sequences in $[0,1)$, and proved some strong and weak convergence theorems for mixed type asymptotically nonexpansive mappings.

Now, we define the hybrid mixed type iteration scheme as follows.

Let $E$ be a real Banach space, $K$ be a nonempty closed convex subset of $E$ and $P: E \rightarrow K$ be a nonexpansive retraction of $E$ onto $K$. Let $S_{1}, S_{2}: K \rightarrow K$ be two asymptotically nonexpansive self mappings and $T_{1}, T_{2}: K \rightarrow E$ be two asymptotically nonexpansive non-self mappings in the intermediate sense. Then the hybrid mixed type iteration scheme for the mentioned mappings is as follows:

$$
\begin{aligned}
x_{1} & =x \in K, \\
x_{n+1} & =P\left(\left(1-\alpha_{n}\right) S_{1}^{n} x_{n}+\alpha_{n} T_{1}\left(P T_{1}\right)^{n-1} y_{n}\right), \\
y_{n} & =P\left(\left(1-\beta_{n}\right) S_{2}^{n} x_{n}+\beta_{n} T_{2}\left(P T_{2}\right)^{n-1} x_{n}\right), n \geq 1,
\end{aligned}
$$

where $\left\{\alpha_{n}\right\}$ and $\left\{\beta_{n}\right\}$ are real sequences in $[0,1)$.

The purpose of this paper is to study newly defined hybrid mixed type iteration scheme (1.6) and establish some strong convergence theorems in the setting of real Banach spaces.

Next, we need the following useful lemma to prove our main results.

Lemma 1.1. (See [14]) Let $\left\{\alpha_{n}\right\}_{n=1}^{\infty},\left\{\beta_{n}\right\}_{n=1}^{\infty}$ and $\left\{r_{n}\right\}_{n=1}^{\infty}$ be sequences of nonnegative numbers satisfying the inequality

$$
\alpha_{n+1} \leq\left(1+\beta_{n}\right) \alpha_{n}+r_{n}, \forall n \geq 1 \text {. }
$$


If $\sum_{n=1}^{\infty} \beta_{n}<\infty$ and $\sum_{n=1}^{\infty} r_{n}<\infty$, then

(i) $\lim _{n \rightarrow \infty} \alpha_{n}$ exists;

(ii) In particular, if $\left\{\alpha_{n}\right\}_{n=1}^{\infty}$ has a subsequence which converges strongly to zero, then $\lim _{n \rightarrow \infty} \alpha_{n}=0$.

\section{Main Results}

In this section, we prove some strong convergence theorems of iteration scheme (1.6) for two asymptotically nonexpansive mappings and two asymptotically nonexpansive non-self mappings in the intermediate sense in real Banach spaces. First, we shall need the following lemma.

Lemma 2.1. Let $E$ be a real Banach space, $K$ be a nonempty closed convex subset of $E$. Let $S_{1}, S_{2}: K \rightarrow K$ be two asymptotically nonexpansive self mappings with sequences $\left\{k_{n}\right\},\left\{l_{n}\right\} \subset[1, \infty)$ such that $\sum_{n=1}^{\infty}\left(k_{n} l_{n}-1\right)<\infty$ and $T_{1}, T_{2}: K \rightarrow E$ be two asymptotically nonexpansive non-self mappings in the intermediate sense. Put

$$
\begin{gathered}
h_{n}=\max \left\{0, \sup _{x, y \in K, n \geq 1}\left(\left\|T_{1}\left(P T_{1}\right)^{n-1}(x)-T_{1}\left(P T_{1}\right)^{n-1}(y)\right\|-\|x-y\|\right),\right. \\
\left.\sup _{x, y \in K, n \geq 1}\left(\left\|T_{2}\left(P T_{2}\right)^{n-1}(x)-T_{2}\left(P T_{2}\right)^{n-1}(y)\right\|-\|x-y\|\right)\right\}
\end{gathered}
$$

such that $\sum_{n=1}^{\infty} h_{n}<\infty$. Let $\left\{x_{n}\right\}$ be the sequence defined by (1.6), where $\left\{\alpha_{n}\right\}$ and $\left\{\beta_{n}\right\}$ are real sequences in $[0,1)$. Suppose that $F=F\left(S_{1}\right) \cap F\left(S_{2}\right) \cap$ $F\left(T_{1}\right) \bigcap F\left(T_{2}\right) \neq \emptyset$. Then $\lim _{n \rightarrow \infty}\left\|x_{n}-q\right\|$ and $\lim _{n \rightarrow \infty} d\left(x_{n}, F\right)$ both exist for any $q \in F$.

Proof. Let $q \in F$. From (1.6) and (2.1), we have

$$
\begin{aligned}
\left\|y_{n}-q\right\| & =\left\|P\left(\left(1-\beta_{n}\right) S_{2}^{n} x_{n}+\beta_{n} T_{2}\left(P T_{2}\right)^{n-1} x_{n}\right)-P(q)\right\| \\
& \leq\left\|\left(1-\beta_{n}\right) S_{2}^{n} x_{n}+\beta_{n} T_{2}\left(P T_{2}\right)^{n-1} x_{n}-q\right\| \\
& =\left\|\left(1-\beta_{n}\right)\left(S_{2}^{n} x_{n}-q\right)+\beta_{n}\left(T_{2}\left(P T_{2}\right)^{n-1} x_{n}-q\right)\right\| \\
& \leq\left(1-\beta_{n}\right)\left\|S_{2}^{n} x_{n}-q\right\|+\beta_{n}\left\|T_{2}\left(P T_{2}\right)^{n-1} x_{n}-q\right\| \\
& \leq\left(1-\beta_{n}\right) l_{n}\left\|x_{n}-q\right\|+\beta_{n}\left[\left\|x_{n}-q\right\|+h_{n}\right] \\
& \leq\left(1-\beta_{n}\right) l_{n}\left\|x_{n}-q\right\|+\beta_{n} l_{n}\left\|x_{n}-q\right\|+\beta_{n} h_{n} \\
& \leq l_{n}\left\|x_{n}-q\right\|+h_{n} .
\end{aligned}
$$


Again from (1.6) and (2.1), we have

$$
\begin{aligned}
\left\|x_{n+1}-q\right\| & =\left\|P\left(\left(1-\alpha_{n}\right) S_{1}^{n} x_{n}+\alpha_{n} T_{1}\left(P T_{1}\right)^{n-1} y_{n}\right)-P(q)\right\| \\
& \leq\left\|\left(1-\alpha_{n}\right) S_{1}^{n} x_{n}+\alpha_{n} T_{1}\left(P T_{1}\right)^{n-1} y_{n}-q\right\| \\
& =\left\|\left(1-\alpha_{n}\right)\left(S_{1}^{n} x_{n}-q\right)+\alpha_{n}\left(T_{1}\left(P T_{1}\right)^{n-1} y_{n}-q\right)\right\| \\
& \leq\left(1-\alpha_{n}\right)\left\|S_{1}^{n} x_{n}-q\right\|+\alpha_{n}\left\|T_{1}\left(P T_{1}\right)^{n-1} y_{n}-q\right\| \\
& \leq\left(1-\alpha_{n}\right) k_{n}\left\|x_{n}-q\right\|+\alpha_{n}\left[\left\|y_{n}-q\right\|+h_{n}\right] \\
& \leq\left(1-\alpha_{n}\right) k_{n}\left\|x_{n}-q\right\|+\alpha_{n}\left\|y_{n}-q\right\|+h_{n} .
\end{aligned}
$$

Using equation (2.2) in (2.3), we obtain

$$
\begin{aligned}
\left\|x_{n+1}-q\right\| \leq & \left(1-\alpha_{n}\right) k_{n}\left\|x_{n}-q\right\|+\alpha_{n}\left[l_{n}\left\|x_{n}-q\right\|+h_{n}\right] \\
& +h_{n} \\
\leq & \left(1-\alpha_{n}\right) k_{n}\left\|x_{n}-q\right\|+\alpha_{n} l_{n}\left\|x_{n}-q\right\|+h_{n} \\
& +h_{n} \\
\leq & \left(1-\alpha_{n}\right) k_{n} l_{n}\left\|x_{n}-q\right\|+\alpha_{n} k_{n} l_{n}\left\|x_{n}-q\right\| \\
& +2 h_{n} \\
= & k_{n} l_{n}\left\|x_{n}-q\right\|+2 h_{n} \\
= & {\left[1+\left(k_{n} l_{n}-1\right)\right]\left\|x_{n}-q\right\|+2 h_{n} . }
\end{aligned}
$$

Since $\sum_{n=1}^{\infty}\left(k_{n} l_{n}-1\right)<\infty$ and $\sum_{n=1}^{\infty} h_{n}<\infty$, it follows from Lemma 1.1 that $\lim _{n \rightarrow \infty}\left\|x_{n}-q\right\|$ exists.

Now, taking the infimum over all $q \in F$ in (2.4), we have

$$
d\left(x_{n+1}, F\right) \leq\left[1+\left(k_{n} l_{n}-1\right)\right] d\left(x_{n}, F\right)+2 h_{n}
$$

for all $n \in \mathbf{N}$, it follows from $\sum_{n=1}^{\infty}\left(k_{n} l_{n}-1\right)<\infty, \sum_{n=1}^{\infty} h_{n}<\infty$ and Lemma 1.1 that $\lim _{n \rightarrow \infty} d\left(x_{n}, F\right)$ exists. This completes the proof.

Theorem 2.2. Let $E$ be a real Banach space, $K$ be a nonempty closed convex subset of $E$. Let $S_{1}, S_{2}: K \rightarrow K$ be two asymptotically nonexpansive self mappings with sequences $\left\{k_{n}\right\},\left\{l_{n}\right\} \subset[1, \infty)$ such that $\sum_{n=1}^{\infty}\left(k_{n} l_{n}-1\right)<\infty$ and $T_{1}, T_{2}: K \rightarrow E$ be two asymptotically nonexpansive non-self mappings in the intermediate sense. Put

$$
\begin{gathered}
h_{n}=\max \left\{0, \sup _{x, y \in K, n \geq 1}\left(\left\|T_{1}\left(P T_{1}\right)^{n-1}(x)-T_{1}\left(P T_{1}\right)^{n-1}(y)\right\|-\|x-y\|\right),\right. \\
\left.\sup _{x, y \in K, n \geq 1}\left(\left\|T_{2}\left(P T_{2}\right)^{n-1}(x)-T_{2}\left(P T_{2}\right)^{n-1}(y)\right\|-\|x-y\|\right)\right\}
\end{gathered}
$$


such that $\sum_{n=1}^{\infty} h_{n}<\infty$. Let $\left\{x_{n}\right\}$ be the sequence defined by (1.6), where $\left\{\alpha_{n}\right\}$ and $\left\{\beta_{n}\right\}$ are real sequences in $[0,1)$. Suppose that $F=F\left(S_{1}\right) \bigcap F\left(S_{2}\right) \bigcap$ $F\left(T_{1}\right) \bigcap F\left(T_{2}\right)$ is nonempty and closed. Then $\left\{x_{n}\right\}$ converges strongly to a common fixed point of $S_{1}, S_{2}, T_{1}$ and $T_{2}$ if and only if $\liminf _{n \rightarrow \infty} d\left(x_{n}, F\right)=$ 0 , where $d(x, F)=\inf \{\|x-p\|: p \in F\}$.

Proof. The necessity is obvious. Indeed, if $x_{n} \rightarrow q \in F$ as $n \rightarrow \infty$, then

$$
d\left(x_{n}, F\right)=\inf _{q \in F} d\left(x_{n}, q\right) \leq\left\|x_{n}-q\right\| \rightarrow 0(n \rightarrow \infty) .
$$

Thus $\liminf \operatorname{in}_{n \rightarrow \infty} d\left(x_{n}, F\right)=0$.

Conversely, suppose that $\liminf _{n \rightarrow \infty} d\left(x_{n}, F\right)=0$. By Lemma 2.1, we have that $\lim _{n \rightarrow \infty} d\left(x_{n}, F\right)$ exists. Further, by assumption $\lim _{n \rightarrow \infty} d\left(x_{n}, F\right)=$ 0 , from (2.5) and Lemma 1.1(ii), we conclude that $\lim _{n \rightarrow \infty} d\left(x_{n}, F\right)=0$. Now, we show that $\left\{x_{n}\right\}$ is a Cauchy sequence in $E$. Indeed, from (2.4), we have

$$
\left\|x_{n+1}-q\right\| \leq\left[1+\left(k_{n} l_{n}-1\right)\right]\left\|x_{n}-q\right\|+2 h_{n}
$$

for each $n \in \mathbf{N}$ with $\sum_{n=1}^{\infty}\left(k_{n} l_{n}-1\right)<\infty, \sum_{n=1}^{\infty} h_{n}<\infty$ and $q \in F$. For any $m, n, m>n \in \mathbf{N}$, we have

$$
\begin{aligned}
\left\|x_{m}-q\right\| & \leq\left[1+\left(k_{m-1} l_{m-1}-1\right)\right]\left\|x_{m-1}-q\right\|+2 h_{m-1} \\
& \leq e^{\left(k_{m-1} l_{m-1}-1\right)}\left\|x_{m-1}-q\right\|+2 h_{m-1} \\
& \vdots \\
& \leq\left(e^{\sum_{i=n}^{m-1}\left(k_{i} l_{i}-1\right)}\right)\left\|x_{n}-q\right\|+2\left(e^{\sum_{i=n+1}^{m-1}\left(k_{i} l_{i}-1\right)}\right) \sum_{i=n}^{m-1} h_{i} \\
& \leq K^{\prime}\left\|x_{n}-q\right\|+2 K^{\prime} \sum_{i=n}^{m-1} h_{i}
\end{aligned}
$$

where $K^{\prime}=e^{\sum_{i=n}^{\infty}\left(k_{i} l_{i}-1\right)}$.

Thus for any $q \in F$, we have

$$
\begin{aligned}
\left\|x_{n}-x_{m}\right\| & \leq\left\|x_{n}-q\right\|+\left\|x_{m}-q\right\| \\
& \leq\left\|x_{n}-q\right\|+K^{\prime}\left\|x_{n}-q\right\|+2 K^{\prime} \sum_{i=n}^{m-1} h_{i} \\
& =\left(K^{\prime}+1\right)\left\|x_{n}-q\right\|+2 K^{\prime} \sum_{i=n}^{m-1} h_{i} .
\end{aligned}
$$


Taking the infimum over all $q \in F$, we obtain

$$
\left\|x_{n}-x_{m}\right\| \leq\left(K^{\prime}+1\right) d\left(x_{n}, F\right)+2 K^{\prime} \sum_{i=n}^{m-1} h_{i} .
$$

Thus it follows from $\lim _{n \rightarrow \infty} d\left(x_{n}, F\right)=0$ and $h_{n} \rightarrow 0$ as $n \rightarrow \infty$ that $\left\{x_{n}\right\}$ is a Cauchy sequence in $K$. Since $K$ is closed subset of $E$, the sequence $\left\{x_{n}\right\}$ converges strongly to some $q^{*} \in K$. Next, we show that $q^{*} \in F$. Now, $\lim _{n \rightarrow \infty} d\left(x_{n}, F\right)=0$ gives that $d\left(q^{*}, F\right)=0$. Since $F$ is closed, $q^{*} \in F$. Thus $q^{*}$ is a common fixed point of $S_{1}, S_{2}, T_{1}$ and $T_{2}$. This completes the proof.

Theorem 2.3. Let $E$ be a real Banach space, $K$ be a nonempty closed convex subset of $E$. Let $S_{1}, S_{2}: K \rightarrow K$ be two asymptotically nonexpansive self mappings with sequences $\left\{k_{n}\right\},\left\{l_{n}\right\} \subset[1, \infty)$ such that $\sum_{n=1}^{\infty}\left(k_{n} l_{n}-1\right)<\infty$ and $T_{1}, T_{2}: K \rightarrow E$ be two asymptotically nonexpansive non-self mappings in the intermediate sense and $h_{n}$ be taken as in Lemma 2.1. Let $\left\{x_{n}\right\}$ be the sequence defined by (1.6), where $\left\{\alpha_{n}\right\}$ and $\left\{\beta_{n}\right\}$ are real sequences in $[0,1)$. Suppose that $F=F\left(S_{1}\right) \bigcap F\left(S_{2}\right) \bigcap F\left(T_{1}\right) \bigcap F\left(T_{2}\right)$ is nonempty. If one of $S_{1}, S_{2}, T_{1}$ and $T_{2}$ is completely continuous and $\lim _{n \rightarrow \infty}\left\|x_{n}-S_{i} x_{n}\right\|=$ $\lim _{n \rightarrow \infty}\left\|x_{n}-T_{i} x_{n}\right\|=0$ for $i=1,2$, then the sequence $\left\{x_{n}\right\}$ converges strongly to a common fixed point of $S_{1}, S_{2}, T_{1}$ and $T_{2}$.

Proof. Without loss of generality we can assume that $S_{1}$ is completely continuous. Since $\left\{x_{n}\right\}$ is bounded by Lemma 2.1, there exists a subsequence $\left\{S_{1} x_{n_{k}}\right\}$ of $\left\{S_{1} x_{n}\right\}$ such that $\left\{S_{1} x_{n_{k}}\right\}$ converges strongly to some $q_{*} \in K$. Moreover, by hypothesis of the theorem we know that

$$
\lim _{k \rightarrow \infty}\left\|x_{n_{k}}-S_{1} x_{n_{k}}\right\|=\lim _{k \rightarrow \infty}\left\|x_{n_{k}}-S_{2} x_{n_{k}}\right\|=0
$$

and

$$
\lim _{k \rightarrow \infty}\left\|x_{n_{k}}-T_{1} x_{n_{k}}\right\|=\lim _{k \rightarrow \infty}\left\|x_{n_{k}}-T_{2} x_{n_{k}}\right\|=0
$$

which implies that

$$
\left\|x_{n_{k}}-q_{*}\right\| \leq\left\|x_{n_{k}}-S_{1} x_{n_{k}}\right\|+\left\|S_{1} x_{n_{k}}-q_{*}\right\| \rightarrow 0
$$

as $k \rightarrow \infty$ and so $x_{n_{k}} \rightarrow q_{*} \in K$. Thus, by the continuity of $S_{1}, S_{2}, T_{1}$ and $T_{2}$, we have

$$
\left\|q_{*}-S_{i} q_{*}\right\|=\lim _{k \rightarrow \infty}\left\|x_{n_{k}}-S_{i} x_{n_{k}}\right\|=0
$$

and

$$
\left\|q_{*}-T_{i} q_{*}\right\|=\lim _{k \rightarrow \infty}\left\|x_{n_{k}}-T_{i} x_{n_{k}}\right\|=0
$$


for $i=1,2$. Thus it follows that $q_{*} \in F=F\left(S_{1}\right) \bigcap F\left(S_{2}\right) \bigcap F\left(T_{1}\right) \bigcap F\left(T_{2}\right)$. Again, since $\lim _{n \rightarrow \infty}\left\|x_{n}-q_{*}\right\|$ exists by Lemma 2.1, we have $\lim _{n \rightarrow \infty} \| x_{n}-$ $q_{*} \|=0$. This shows that the sequence $\left\{x_{n}\right\}$ converges strongly to a common fixed point of $S_{1}, S_{2}, T_{1}$ and $T_{2}$. This completes the proof.

Theorem 2.4. Let $E$ be a real Banach space, $K$ be a nonempty closed convex subset of $E$. Let $S_{1}, S_{2}: K \rightarrow K$ be two asymptotically nonexpansive self mappings with sequences $\left\{k_{n}\right\},\left\{l_{n}\right\} \subset[1, \infty)$ such that $\sum_{n=1}^{\infty}\left(k_{n} l_{n}-1\right)<\infty$ and $T_{1}, T_{2}: K \rightarrow E$ be two asymptotically nonexpansive non-self mappings in the intermediate sense and $h_{n}$ be taken as in Lemma 2.1. Let $\left\{x_{n}\right\}$ be the sequence defined by (1.6), where $\left\{\alpha_{n}\right\}$ and $\left\{\beta_{n}\right\}$ are real sequences in $[0,1)$. Suppose that $F=F\left(S_{1}\right) \bigcap F\left(S_{2}\right) \bigcap F\left(T_{1}\right) \bigcap F\left(T_{2}\right)$ is nonempty. If one of $S_{1}, S_{2}, T_{1}$ and $T_{2}$ is semi-compact and $\lim _{n \rightarrow \infty}\left\|x_{n}-S_{i} x_{n}\right\|=\lim _{n \rightarrow \infty} \| x_{n}-$ $T_{i} x_{n} \|=0$ for $i=1,2$, then the sequence $\left\{x_{n}\right\}$ converges strongly to a common fixed point of $S_{1}, S_{2}, T_{1}$ and $T_{2}$.

Proof. Since by hypothesis $\lim _{n \rightarrow \infty}\left\|x_{n}-S_{i} x_{n}\right\|=\lim _{n \rightarrow \infty}\left\|x_{n}-T_{i} x_{n}\right\|=0$ for $i=1,2$ and one of $S_{1}, S_{2}, T_{1}$ and $T_{2}$ is semi-compact, there exists a subsequence $\left\{x_{n_{j}}\right\}$ of $\left\{x_{n}\right\}$ such that $\left\{x_{n_{j}}\right\}$ converges strongly to some $p_{*} \in$ $K$. Moreover, by the continuity of $S_{1}, S_{2}, T_{1}$ and $T_{2}$, we have $\left\|p_{*}-S_{i} p_{*}\right\|=$ $\lim _{j \rightarrow \infty}\left\|x_{n_{j}}-S_{i} x_{n_{j}}\right\|=0$ and $\left\|p_{*}-T_{i} p_{*}\right\|=\lim _{j \rightarrow \infty}\left\|x_{n_{j}}-T_{i} x_{n_{j}}\right\|=0$ for $i=1,2$. Thus it follows that $p_{*} \in F=F\left(S_{1}\right) \bigcap F\left(S_{2}\right) \bigcap F\left(T_{1}\right) \bigcap F\left(T_{2}\right)$. Since $\lim _{n \rightarrow \infty}\left\|x_{n}-p_{*}\right\|$ exists by Lemma 2.1, we have $\lim _{n \rightarrow \infty}\left\|x_{n}-p_{*}\right\|=0$. This shows that the sequence $\left\{x_{n}\right\}$ converges strongly to a common fixed point of $S_{1}, S_{2}, T_{1}$ and $T_{2}$. This completes the proof.

Theorem 2.5. Let $E$ be a real Banach space, $K$ be a nonempty closed convex subset of $E$. Let $S_{1}, S_{2}: K \rightarrow K$ be two asymptotically nonexpansive self mappings with sequences $\left\{k_{n}\right\},\left\{l_{n}\right\} \subset[1, \infty)$ such that $\sum_{n=1}^{\infty}\left(k_{n} l_{n}-1\right)<\infty$ and $T_{1}, T_{2}: K \rightarrow E$ be two asymptotically nonexpansive non-self mappings in the intermediate sense and $h_{n}$ be taken as in Lemma 2.1. Let $\left\{x_{n}\right\}$ be the sequence defined by (1.6), where $\left\{\alpha_{n}\right\}$ and $\left\{\beta_{n}\right\}$ are real sequences in $[0,1)$. Suppose that $F=F\left(S_{1}\right) \bigcap F\left(S_{2}\right) \cap F\left(T_{1}\right) \bigcap F\left(T_{2}\right)$ is nonempty. If $S_{1}, S_{2}$, $T_{1}$ and $T_{2}$ satisfy the following conditions:

(i) $\lim _{n \rightarrow \infty}\left\|x_{n}-S_{i} x_{n}\right\|=\lim _{n \rightarrow \infty}\left\|x_{n}-T_{i} x_{n}\right\|=0$ for $i=1,2$;

(ii) there exists a continuous function $f:[0, \infty) \rightarrow[0, \infty)$ with $f(0)=0$ and $f(t)>0$ for all $t \in(0, \infty)$ such that

$$
f(d(x, F)) \leq a_{1}\left\|x-S_{1} x\right\|+a_{2}\left\|x-S_{2} x\right\|+a_{3}\left\|x-T_{1} x\right\|+a_{4}\left\|x-T_{2} x\right\|
$$

for all $x \in K$, and $a_{1}, a_{2}, a_{3}, a_{4}$ are nonnegative real numbers such that $a_{1}+a_{2}+a_{3}+a_{4}=1$, where $d(x, F)=\inf \{\|x-p\|: p \in F\}$. 
Then the sequence $\left\{x_{n}\right\}$ converges strongly to a common fixed point of $S_{1}$, $S_{2}, T_{1}$ and $T_{2}$.

Proof. It follows from the hypothesis that

$$
\begin{aligned}
\lim _{n \rightarrow \infty} f\left(d\left(x_{n}, F\right)\right) \leq & a_{1} \cdot\left\|x_{n}-S_{1} x_{n}\right\|+a_{2} \cdot\left\|x_{n}-S_{2} x_{n}\right\| \\
& +a_{3} \cdot\left\|x_{n}-T_{1} x_{n}\right\|+a_{4} \cdot\left\|x_{n}-T_{2} x_{n}\right\| \\
= & 0 .
\end{aligned}
$$

That is,

$$
\lim _{n \rightarrow \infty} f\left(d\left(x_{n}, F\right)\right)=0 .
$$

Since $f:[0, \infty) \rightarrow[0, \infty)$ is a continuous function and $f(0)=0$, therefore we have

$$
\lim _{n \rightarrow \infty} d\left(x_{n}, F\right)=0 .
$$

Therefore, Theorem 2.2 implies that $\left\{x_{n}\right\}$ must converges strongly to a common fixed point of $S_{1}, S_{2}, T_{1}$ and $T_{2}$. This completes the proof.

Example 2.1. Let $X=\mathbb{R}, K=\left[-\frac{1}{\pi}, \frac{1}{\pi}\right],|\lambda|<1$ and $P$ be the identity mapping. For each $x \in K$, define two mappings $S, T: K \rightarrow K$ by

$$
T(x)=\left\{\begin{array}{cl}
\lambda x \sin (1 / x), & \text { if } x \neq 0 \\
0, & \text { if } x=0 .
\end{array}\right.
$$

and

$$
S(x)= \begin{cases}x, & \text { if } x \neq 0 \\ 0, & \text { if } x=0\end{cases}
$$

Then $\left\{T^{n} x\right\} \rightarrow 0$ uniformly on $K$ as $n \rightarrow \infty$. Thus

$$
\limsup _{n \rightarrow \infty}\left\{\left|T^{n} x-T^{n} y\right|-|x-y| \vee 0\right\}=0
$$

for all $x, y \in K$. Hence $T$ is an asymptotically nonexpansive mapping in the intermediate sense (ANI in short), but it is not a Lipschitz mapping and $S$ is an asymptotically nonexpansive mapping with constant sequence $\left\{k_{n}\right\}=\{1\}$ for all $n \in \mathbf{N}$ and uniformly $L$-Lipschitzian with $L=\sup _{n \geq 1}\left\{k_{n}\right\}$. Also $F(T)=\{0\}$ is the unique fixed point of $T$ and $F(S)=\{0\}$ is the unique fixed point of $S$, that is, $F=F(S) \cap F(T)=\{0\}$ is the unique hybrid common fixed point of $S$ and $T$. 


\section{Concluding remarks}

In this paper, we study hybrid mixed type iteration scheme for two asymptotically nonexpansive self mappings and two asymptotically nonexpansive non-self mappings in the intermediate sense and establish some strong convergence theorems using completely continuous and semi-compactness conditions. Our results extend and generalize the corresponding results of $[1,2$, 9-16].

\section{Acknowledgement}

The author is grateful to the anonymous learned referee for his careful reading and useful suggestions on the manuscript.

\section{References}

[1] E. U. Ofoedu and H. Zegeye C. E. Chidume, Strong and weak convergence theorems for asymptotically nonexpansive mappings, J. Math. Anal. Appl., 280, (2003), $364-374$

[2] N. Shahzad and H. Zegeye C. E. Chidume, Convergence theorems for mappings which are asymptotically nonexpansive in the intermediate sense, Numerical Functional and Optimization, 25(3-4), (2004), 239-257

[3] K. Goebel and W. A. Kirk, A fixed point theorem for asymptotically nonexpansive mappings, Proc. Amer. Math. Soc., 35(1), (1972), 171-174

[4] S. H. Khan and S. Akbulut B. Gunduz, On convergence of an implicit iterative algorithm for non-self asymptotically nonexpansive mappings, Hacettepe J. Math. Stats., 43(3), (2014), 399-411

[5] B. Gunduz and S. Akbulut, On weak and strong convergence theorems for a finite family of non-self $I$-asymptotically nonexpansive mappings, Math. Moravica, 19(2), (2015), 49-64

[6] B. Gunduz, A new multistep iteration for a finite family of asymptotically quasinonexpansive mappings in convex metric spaces, J. Nonlinear Sci. Appl., 9, (2016), $1365-1372$

[7] B. Gunduz, Fixed points of a finite family of $I$-asymptotically quasi-nonexpansive mappings in a convex metric space, Filomat, 31(7), (2017), 2175-2182

[8] B. Gunduz and S. Akbulut, Common fixed points of a finite family of $I$ asymptotically nonexpansive mappings by S-iteration process in Banach spaces, Thai J. Math., 15(3), (2017), 673-687 
[9] Y. J. Cho and W. Guo W. P. Guo, Convergence theorems for mixed type asymptotically nonexpansive mappings, Fixed Point Theory and Appl., 2012:224, (2012)

[10] S. H. Khan and W. Takahashi, Approximating common fixed points of two asymptotically nonexpansive mappings, Sci. Math. Jpn., 53(1), (2001), 143-148

[11] M. O. Osilike and S. C. Aniagbosor, Weak and strong convergence theorems for fixed points of asymptotically nonexpansive mappings, Math. Comput. Modelling, 32, (2000), 1181-1191

[12] B. E. Rhoades, Fixed point iteration for certain nonlinear mappings, J. Math. Anal. Appl., 183, (1994), 118-120

[13] J. Schu, Weak and strong convergence to fixed points of asymptotically nonexpansive mappings, Bull. Austral. Math. Soc., 43(1), (1991), 153-159

[14] K. K. Tan and H. K. Xu, Approximating fixed points of nonexpansive mappings by the Ishikawa iteration process, J. Math. Anal. Appl., 178, (1993), 301-308

[15] L. Wang, Strong and weak convergence theorems for common fixed point of nonself asymptotically nonexpansive mappings, J. Mth. Anal. Appl., 323(1), (2006), 550-557

[16] S. Wei and W. P. Guo, Strong convergence theorems for mixed type asymptotically nonexpansive mappings, Comm. Math. Res., 31, (2015), 149-160

Received: 31.10 .2016

Accepted: 25.01.2018

Revised: 21.01 .2018 